\title{
Search for a hidden goal by Clark's nutcrackers (Nucifraga columbiana) is more accurate inside than outside a landmark array
}

\author{
BRETT M. GIBSON and ALAN C. KAMIL \\ University of Nebraska, Lincoln, Nebraska
}

\begin{abstract}
In three experiments in which an open-room delayed response task was used, we explored how Clark's nutcrackers use landmarks to search for a hidden goal when multiple potential goal locations were present. In Experiment 1, nutcrackers presented with three spatial samples were able to use relative local cues from an array that changed positions throughout a session to return to a hidden goal during a test. In Experiment 2, the number of samples varied from one to three prior to the test. The nutcrackers performed as well with one sample as with two or three samples. In Experiment 3, we attempted to increase the cost of searching for the goal but, in contrast to previous reports with nutcrackers, found no improvement in search accuracy. Across all experiments, search accuracy varied reliably for different goal locations, but the pattern of performance at each location was generally consistent. This result suggests that nutcrackers may be using different types of spatial information, depending on goal-landmark relationships.
\end{abstract}

The purpose of these experiments was to investigate how animals use landmarks to search for a hidden goal when multiple potential goal locations are present. Many tests of navigation examine how animals use information provided by landmarks to find a single goal location (for reviews, see Cheng \& Spetch, 1998; Shettleworth, 1998). In these experiments, animals are first trained to find a unique goal location defined by its stable relationship to the location of various landmarks (e.g., Cheng, 1988; Chittka, Geiger, \& Kunze, 1995; Spetch et al., 1997; Tinbergen, 1972; Vander Wall, 1982). After this initial training, some feature of the landmark array is transformed, altering the geometric relationship between one or more of the landmarks and the goal. Performance on these test trials is used to discern the spatial information animals may use during way-finding. Collett, Cartwright, and Smith (1986) used such an approach to explore the spatial abilities of gerbils. In that study, gerbils were trained to locate a goal that was positioned in front of and between two landmarks. When the distance between the landmarks was doubled during a subsequent test, the gerbils searched at two locations, each the correct distance and bearing from each landmark. Although the transformational approach has been a useful tool in the investigation of spatial navigation, modifications to the standard design might prove valuable.

This research was supported by NSF Grant IBN 9421807. We thank Sara J. Shettleworth and two anonymous reviewers for their comments that improved the content and clarity of this manuscript. We also thank Chris S., Juli J., and Keri B., whose assistance throughout the study was appreciated. Correspondence concerning this article should be addressed to B. M. Gibson, Department of Psychology, University of Toronto, 100 St. George Street, Room 4020, Toronto, ON M5S 3G3, Canada (e-mail: gibson@psych.utoronto.ca).
Most transformational studies in the laboratory use a single goal location (e.g., Cartwright \& Collett, 1983), but in the natural environment many animals may need to track multiple locations, using cues provided by a single set of landmarks. One clear example is provided by seedstoring birds - in particular, the Clark's nutcracker-that make thousands of caches during a 3-week period in the autumn (Tomback, 1980; Vander Wall \& Balda, 1981). More than one cache may be made by these birds in the same local environment. Each cache can be defined by a unique set of spatial cues from an array of landmarks present in that environment (Gallistel, 1990). Differences in the spatial relationship between each cache site and the array of landmarks in the environment may be more or less easy to encode, remember, or use, and navigational accuracy may vary with respect to the nature of this spatial information (Basil, 1993; Kamil \& Cheng, 2001). Bennet (1993) trained European jays to find a goal, the position of which was defined by an array of 12 landmarks. Subsequent tests were conducted in which the array was rotated and some of the landmarks in the array removed. Landmarks that were taller and nearer to the goal had more influence over search for the goal during these tests than did landmarks that were smaller or farther from the goal. In addition, it is possible that goal locations that have more landmarks near them may be easier to locate during search than goal sites that have fewer or more dispersed landmarks. Kamil and Cheng have recently developed a multiple bearings model that predicts that search accuracy may vary as a function of the number of landmarks and their relationship to a goal. The results of computer simulations testing this model indicate that increasing the number of landmarks used resulted in increasing search accuracy. Therefore, an approach in which animals are re- 
quired to locate a hidden goal that can be positioned at a large number of different locations with respect to a landmark array might prove worthwhile.

Delayed response tasks have been a valuable tool in the study of animal learning and cognition (Catania, 1992; Riley, 1968; Shettleworth, 1998). Recently, variations of the delayed matching-to-sample (DMTS) paradigm have been usefully applied to issues of spatial cognition. Brodbeck (1994) used procedures similar to DMTS to investigate the spatial cues that controlled search for a goal in an open room. Tests following different transformations of the feeder array revealed that food-storing chickadees, but not juncos, responded primarily to global spatial cues over other types of information. Likewise, the radial maze paradigm has had a long history of use in the investigation of spatial cognition (e.g., Olton \& Samuelson, 1976). Beatty and Shavalia (1980) allowed rats to find a reward in each of four arms of an eight-arm radial maze. Following a retention interval, all eight arms were opened and the arms previously not visited were baited. The rats performed better than chance up to $24 \mathrm{~h}$ after their last choice.

In the present study, animals were presented with multiple spatial samples in which the position of a goal, located in the vicinity of a landmark array, was revealed. During a subsequent test, the animals had to choose among 15 previously encountered locations in order to return to the correct position of the goal. This feature of our design is similar to standard radial maze procedures that have animals choose from a large number of alternative spatial locations. Unlike these standard radial maze procedures, however, the animals in the present study were reinforced for selecting the location they had experienced on the previous trial (win-stay response), whereas radial maze procedures often reinforce a win-shift response following four initial choices (although not exclusively; see, e.g., McDonald \& White, 1993). In addition, unlike radial maze designs, the animals were free to move in the open room during search.

Although a variety of organisms could be tested with these procedures, the Clark's nutcracker (Nucifraga columbiana) appears to be an ideal choice. Clark's nutcrackers live in alpine environments in western North America. During a 3-week period each fall, thousands of seeds from pine trees become available for harvesting by nutcrackers. Clark's nutcrackers cache tens of thousands of the pine seeds in thousands of spatially unique locations at distances extending up to $22 \mathrm{~km}$ away from the collection site (Balda \& Kamil, 1998; Vander Wall \& Balda, 1981). During the winter and early spring, when weather conditions are extremely harsh, nutcrackers rely almost exclusively on the recovery of these caches as their primary energy source for reproduction and survival (Giuntoli \& Mewaldt, 1978). Experimental evidence indicates that nutcrackers have a spatial memory for the location of caches made previously (Balda \& Kamil, 1992; Kamil $\&$ Balda, 1985). Spatial memory for a cache site, however, may only be part of a broader spatial-cognitive mecha- nism specialized for the efficient recovery of a large number of spatially dispersed and unmarked caches. Specifically, we have recently begun to explore how nutcrackers may be using spatial information in their environment, especially from landmarks, to navigate and return to a specific goal location (Gould-Beierle \& Kamil, 1998; Kamil \& Jones, 1997).

Delayed response and transformational task procedures are well suited for understanding how different stimulus information leads to differential responding in space. The present experiments employed features of these designs to investigate the fine-grained spatial cognitive abilities of Clark's nutcrackers. Nutcrackers were presented with a landmark array that was moved in the room from trial to trial. The birds were required to use relative spatial information provided by the array to locate a hidden goal positioned at 1 of 15 potential goal locations. Using these procedures, we investigated how the spatial relationship between a goal and a set of landmarks affects Clark's nutcrackers' search when multiple potential goal locations are present.

\section{EXPERIMENT 1}

We examined the ability of Clark's nutcrackers to use landmark information to locate a buried goal in a dynamic situation in which the location to be remembered changed from trial to trial. Nutcrackers were presented with a fixed array of three uniquely marked landmarks. A grid of 15 potential goal locations that overlapped with areas located within and outside the perimeter of the landmark array was hidden underneath a layer of cellulose bedding. The goal locations were fixed with respect to the landmark array. For each session, 1 of the 15 goal locations was selected. During a daily session, the nutcrackers first had three samples (or trials) in which a marker was placed at the goal to reveal its position. On the fourth trial of the session, the test, the marker indicating the goal location was removed, and the bird was allowed to dig freely in the room. Between each of the samples and the test, the array with the goal was rotated and moved within the room. In order to return accurately to the correct position during the test, the nutcrackers would need to remember relative landmark array-goal relationships, encoded during the session.

\section{Method}

\section{Subjects}

Five adult nutcrackers (Nucifraga columbiana) served in all three experiments. The nutcrackers were trapped in an alpine habitat as adults and individually housed in large cages in a multispecies colony at the University of Nebraska-Lincoln. All the birds had previous experience in other open-field experiments (GouldBeierle \& Kamil, 1996). The nutcrackers were kept under a 14:10h light:dark cycle and were maintained between $85 \%$ and $90 \%$ of their free-feeding weight. All the birds had ad-lib access to water and were fed a diet composed of turkey starter, pigeon pellets, sunflower seeds, pine seeds, grubs, and vitamin supplements. 


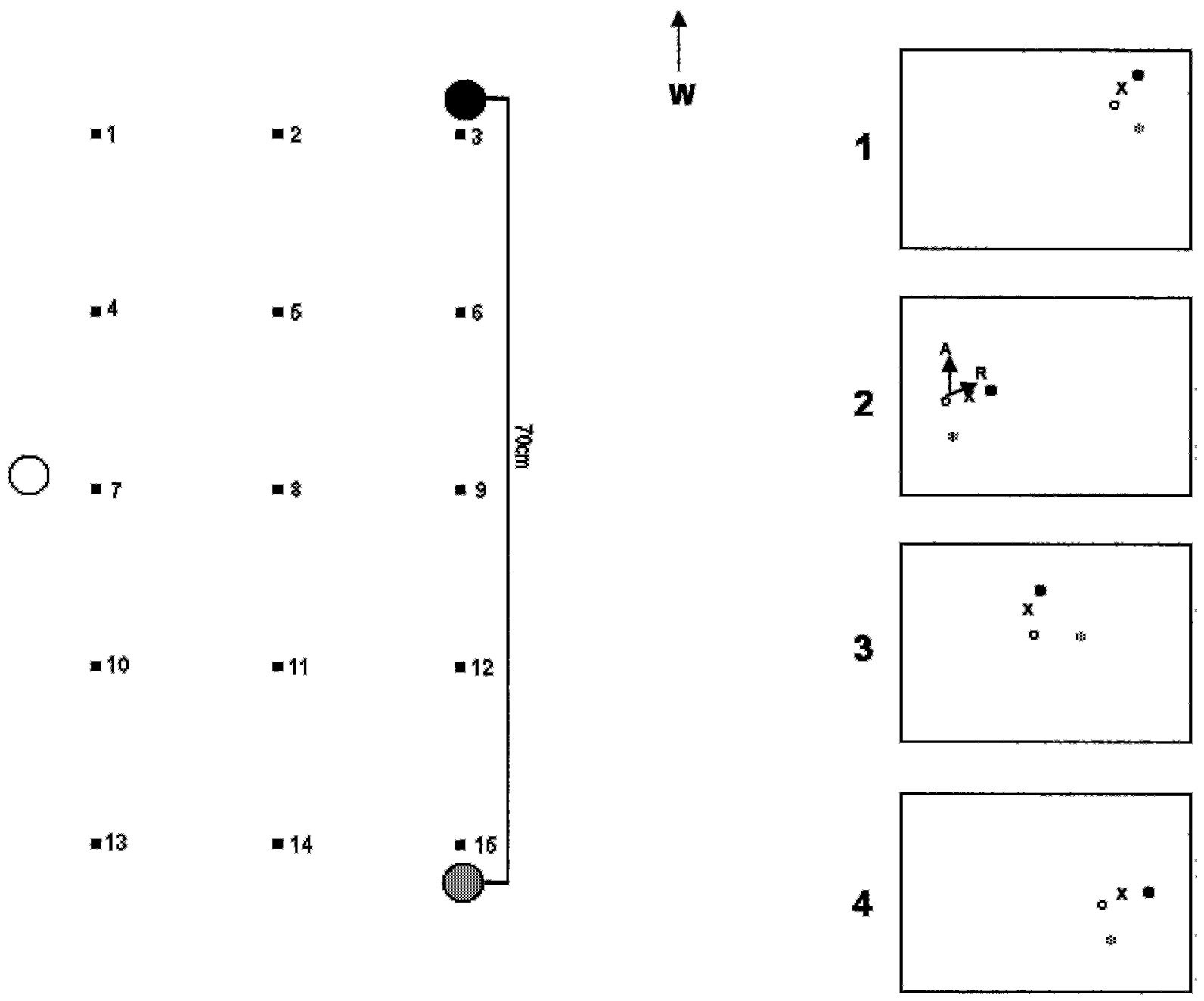

Figure 1. Left: Top-down view of the landmark array and the $\mathbf{1 5}$ goal locations. Each landmark is represented by a circle (black filled circle, green landmark; unfilled circle, white landmark; gray filled circle, yellow landmark). Right: View of the array being rotated and translated in the room across each of four trials, as it might occur in a typical session. The lowercase $x$ marks the location of the goal in this example. The two arrows in the second trial indicate the direction of search if nutcrackers were using either an absolute bearing $(A)$ or relative bearings from more than one landmark $(R)$.

\begin{abstract}
Apparatus
Experimental room. Testing was conducted in a $4.4 \times 2.7 \mathrm{~m}$ room. The floor of the room was covered with cellulose animal bedding at a depth of 4-6 cm. The walls were painted light beige and had posters mounted on them. A door, through which the experimenter could enter and withdraw from the room, was located on the east wall. A smoked glass observation window was also located on this wall, as was an opaque sliding door through which the nutcrackers entered and departed the room. Four 80-W fluorescent lighting fixtures provided even illumination. A Panasonic WVBL200 closed-circuit camera, with a 4.5-mm (1:1.4) wide-angle lens, mounted in the ceiling of the room was used to record the position of the landmark array and digs made by the nutcrackers. A transfer cage located in an observation area outside the east wall of the experimental room housed the nutcrackers temporarily between tests. Video recording equipment, used to record each session on videotape, was also kept in the observation area. Background white noise was projected into the room from a speaker located below the sliding door.
\end{abstract}

Landmark array. A landmark array was used to provide local cues for navigation to the goal. The array consisted of three cylindrical landmarks, each $40 \mathrm{~cm}$ tall and $4.5 \mathrm{~cm}$ in diameter (Figure 1). The landmarks formed a right triangle, with the length of its sides proportional to a 3-4-5 ratio. Each landmark was painted a unique color. The geometric configuration of the landmarks was fixed across all the experiments. To reduce the influence of global cues on navigation-that is, the spatial information obtained from the room itself (e.g., shape of the room, doors, etc.) - the landmark array was moved and rotated to different positions in the room across each trial of a session (see below). Below the cellulose substrate, and unseen by the nutcrackers, was a square grid of 64 marked points, each separated by $25 \mathrm{~cm}$. Prior to the start of each phase of a session, one of these 64 points was selected at random, and the geometric center of the landmark array was aligned with this point. In addition, the landmark array was rotated $0^{\circ}, 15^{\circ}$, or $30^{\circ}$ clockwise or counterclockwise on its geometric center. The degree and direction of rotation on each phase was determined according to a block randomized schedule. 
Test locations. Fifteen unseen goal locations (or test locations), lying within and outside the perimeter of the landmark array, made up the test area (Figure 1). Each goal location was a fixed point on an imaginary $3 \times 5$ matrix $(32 \times 64 \mathrm{~cm})$. Goal locations were separated by a distance of $16 \mathrm{~cm}$ either horizontally or vertically. The geometric relationship among each of the 15 test locations and the landmarks in the array always remained the same.

\section{Procedure}

Acclimation. Acclimation trials were conducted to familiarize the birds with the open-room testing environment. Four pine seeds were placed in pseudorandom locations on the bedding prior to the start of a trial. Pine seeds are an important part of the nutcracker's diet and have been used as rewards in previous experiments (Kamil $\&$ Balda, 1985; Olson, 1991). The nutcrackers were individually released into the room and were allowed to search for the seeds until either $20 \mathrm{~min}$ had passed or all the pine seeds had been consumed. The lights in the experimental room were then turned off, a light in the observation room was turned on, and the sliding door opened. This light source served as a cue for the nutcrackers to return to the transfer cage. After some trials, the birds had to be gently prompted to fly to the opening. The nutcrackers rarely required physical prompting after the first 2 weeks of training. Once the bird was in the transfer cage, the sliding door was closed. During the subsequent 2-min intertrial interval (ITI), the experimenter restocked the room with four pine seeds and lightly swept the surface of the bedding to redistribute material and remove marks created during the trial. Following the conclusion of the ITI, acclimation procedures were repeated. The birds experienced one session of two acclimation trials per day. Following the conclusion of the session, the nutcrackers were returned to their home cages. The order in which the birds were acclimated to the room was determined randomly each day. Acclimation continued until a bird had consumed all eight seeds for 3 consecutive days.

Training. Four phases of training were used to shape digging to the area below a red ring (2.54-cm diameter) indicating the position of a hidden goal. For each phase, four training trials were conducted in a session. One session of training was conducted per day. A bird was advanced into a subsequent phase of training if it recovered all eight pine seeds in a day for 3 consecutive days. During Phase 1, the nutcrackers were individually released into the room, and two pine seeds were presented in the center of the red ring. Both the seeds and the ring sat on top of a plastic gray film cap $(3 \mathrm{~cm}$ in diameter) placed on top of the cellulose bedding. The location of the assembly of the ring, seeds, and cap varied randomly within the room from trial to trial. The nutcrackers were allowed $20 \mathrm{~min}$ to find and consume the seeds.

In Phases 2 and 3, we "faded out" the seeds and lens cap as physical cues. During Phase 2, the seeds were partially buried in the substrate within the center of the ring. Likewise, the gray film cap was completely buried approximately $1 \mathrm{~cm}$ below the marker and seeds. In Phase 3, the seeds were situated on top of the gray film cap, all of which were completely buried approximately $2-3 \mathrm{~cm}$ below the surface of the cellulose substrate. Only the red marker indicated the position of the buried goal.

The landmark array was introduced during Phase 4 of training after the subjects had learned to reliably dig below the red ring. The position of the goal varied randomly within and just outside the perimeter of the array. None of the goal positions presented during testing were used during training. During Phase 4 of training, and continuing through testing, the landmark array was moved and rotated (as described above) within the room across trials. Training lasted between 20 and 30 sessions.

Testing. There were four trials to each daily session during testing, the last of which was a test. The first three trials of a session were rewarded samples, during which the birds were shown the location of the buried goal, using the red ring as described above. A 2-min ITI followed each sample. After the conclusion of the ITI fol- lowing the third sample, a test was conducted in which the goal was completely buried at the same relative location but the ring was absent. For each of the three samples and the test, the nutcrackers were individually released into the room and allowed up to $10 \mathrm{~min}$ to locate the goal. This time limit was never exceeded during the sample trials, however, since the ring indicated the position of the goal. The nutcrackers were allowed to make up to 100 digs during the test. A dig was operationally defined as the position at which a bird placed and subsequently removed its beak from the substrate.

The landmark array was moved and rotated before each trial (see the Landmark Array section, above) so that the global position of the goal within the room was different for each trial. One of the 15 goal locations was randomly selected for each session. The order in which the birds experienced each of the 15 goal locations was randomized across a block of 15 trials. No more than 2 nutcrackers were tested at the same position during a day. Testing extended for four blocks, for a total of 60 sessions.

\section{Measures}

The $x-y$ position (relative to the room) of each of the landmarks, the goal location, and the first 20 digs were determined for each trial of each session. The coordinates of these points of interest were calculated by using video playback software that could freeze a frame of the video from each session on a computer screen. A cursor on the screen could be placed over the critical image (landmark, beak in substrate), and the room coordinate of the particular object of interest was recorded. For each test, the distance of each dig from the goal location was calculated. This measure was used as an indicator of accuracy. Because nutcrackers may occasionally explore locations in an open room far removed from the vicinity of a goal area (e.g., Kamil \& Balda, 1990) that do not reflect performance during search for a goal, we scored only those digs that were within the perimeter of a $35 \times 35 \mathrm{~cm}$ square centered on the goal location. This region was selected on the basis of our initial observations indicating that most of the birds' digs fell within this area. In analyses that used more than one goal location (see the analysis section below), digs were only considered as outliers if they fell outside both of the square regions centered on each of the goal locations. Fewer than $5 \%$ of the digs were excluded as outliers from the analyses in any experiment.

\section{Analyses}

Two measures were developed to test whether search was accurately oriented toward the correct goal position. The first took advantage of the fact that the position of the goal with respect to the landmark array remained fixed, whereas the position of the array moved within the room across all four trials of a session. Initially, the nutcrackers may have searched at two potential locations, the location of the goal as defined by the landmarks (local position) or the position of the goal as defined by room cues or by its absolute position in the room during the previous trial (global position). As the landmark array moved across the room from trial to trial, the landmarks always indicated the correct position of the goal (local position), whereas the use of global or room cues encoded during the previous trial would lead to an incorrect response. If the nutcrackers had learned to identify the location of the goal relative to the shifting landmark array (local position), rather than with respect to room cues (global location), their search on the test trial should have been closer to the actual goal location (local position) than to any of the globally defined locations used during the three sample trials. This approach also allowed us to examine for any effects of proactive interference for the location of the goal during the previous trial. Therefore, the distance between each dig made during the test was measured from the local position of the goal defined during the test and also from each of the three global positions defined by the location of the goal in the room during the first three trials of the session. A within-subjects analysis of variance (ANOVA), with bird, block, and trial as factors and accuracy as a dependent 


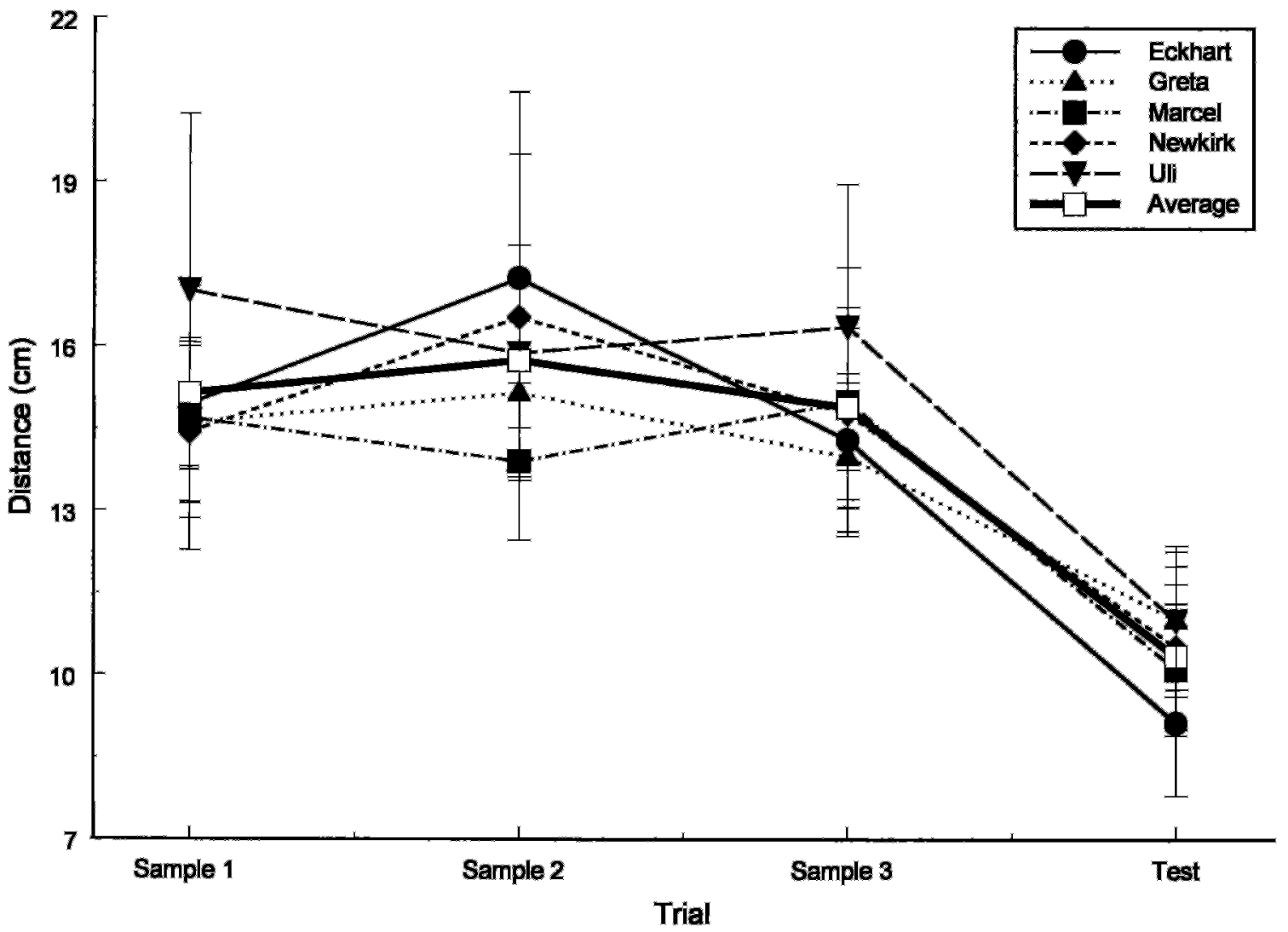

Figure 2. The average distance of digs made during the test from the global positions of the goal across each trial of a session for each bird.

factor, was performed. If the nutcrackers were using local cues to navigate to the goal during the test, the distance of the digs from the goal location on the test should be much lower, on average, than the distance of the same digs from each of the globally defined positions of the goal experienced on the previous three samples.

The second analysis took advantage of the fact that the global location of the test position on any day of testing was independent of its global position on any other test day. To assess whether the distribution of digs during a test was independent of the distribution of digs during other tests, the distance of digs from the goal on a test during a given day was computed and compared with the distance of the same digs from the goal on the other days. Therefore, we compared the distance between digs and the goal with the distance between these same digs and the global location of the goal 1 or 2 days before and 1 or 2 days after the selected day. The measure was calculated for each day of testing possible. The data were then subjected to a repeated measures ANOVA with bird, block, and day as repeated factors and distance of digs from the goal (accuracy) as a dependent measure.

Finally, we examined whether search accuracy on the test varied as a function of test position. For this analysis, we performed a within-subjects ANOVA, with test position and bird as factors and accuracy as a dependent measure. Bonferroni multiple follow-up comparisons were used to examine specific differences in accuracy among positions within the test area. Alpha was set at .05.

\section{Results}

As is shown in Figure 2, all 5 nutcrackers were able to use local cues to locate the goal during the test. The aver- age distance from the goal of digs made during the test was significantly shorter than the distance of the same digs to the global position of the goal on the previous three samples $[F(3,12)=33.49, p<.01]$. This finding indicates there was no proactive interference for the location of the goal on the previous trial. The results from the analysis assessing the independence of digs revealed that the distance of digs from the goal on each day of testing (Figure 3) was reliably shorter than the distance of the same digs from the global position of the goal either 1 or 2 days before or 1 or 2 days after the test day $[F(4,16)=$ $40.08, p<.01]$. The effect of block in this analysis was not apparent $[F(3,12)<1]$. Three of the 5 birds showed an improvement in performance across the first three blocks (data not shown), although across all birds and blocks, this trend only approached significance $[F(3,12)=$ $4.30, p>.05]$.

Figure 4 shows that accuracy varied as a function of the location of the goal with respect to the landmark array, $[F(14,56)=3.54, p<.01]$. In general, the nutcrackers were more accurate when tested at positions within the center of the array [e.g., Positions $8($ mean $=8.79 \mathrm{~cm})$ and $3($ mean $=7.19 \mathrm{~cm})]$ than when tested at positions outside the array [e.g., Positions 1 (mean $=15.54 \mathrm{~cm})$ and 14 $($ mean $=11.29 \mathrm{~cm})]$. Accuracy at Position $13($ mean $=$ $19.32 \mathrm{~cm}$ ), one of the locations farthest from the center 


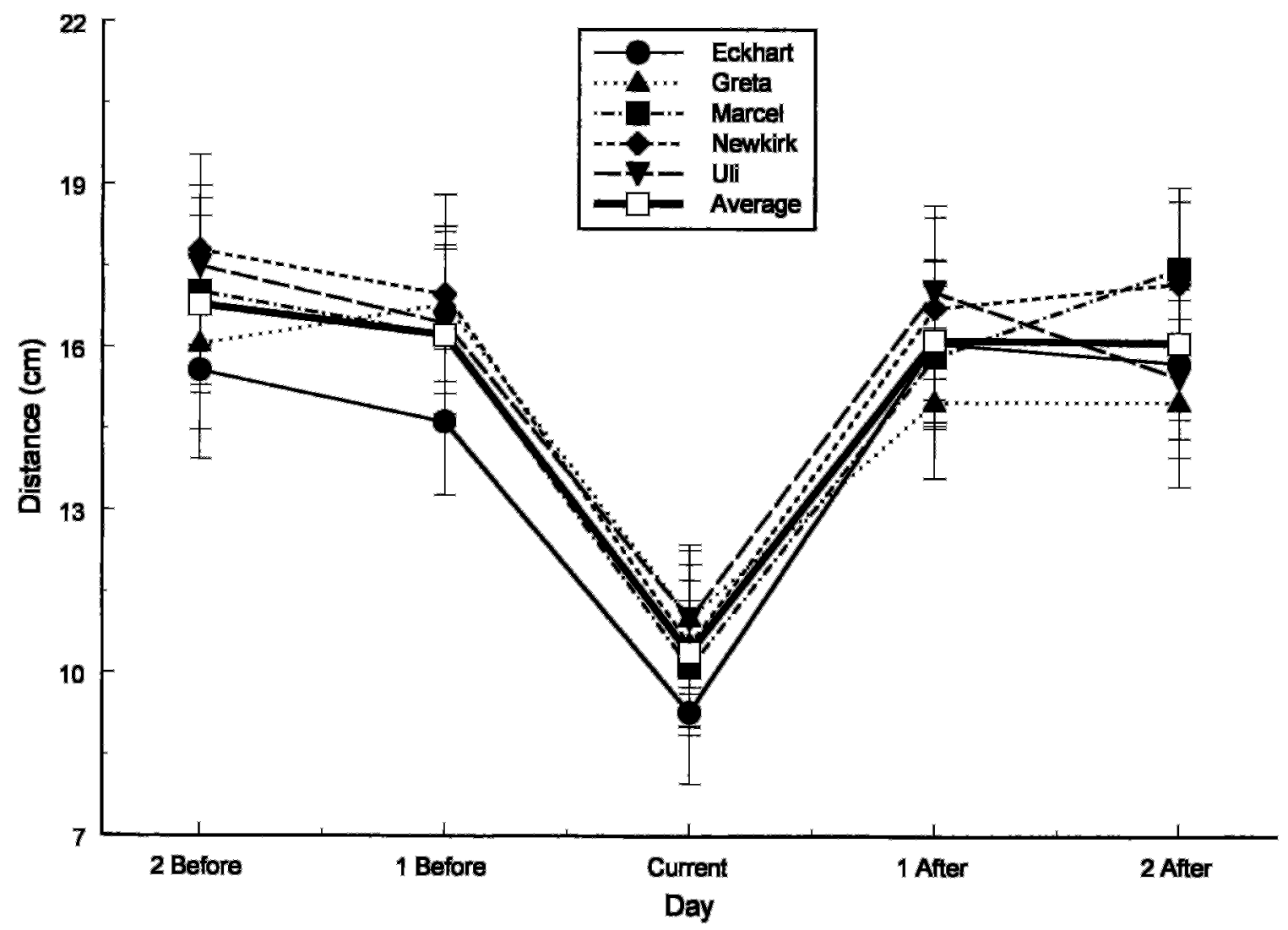

Figure 3. The average distance of digs from the goal on a selected day (current day) from the global position of the goal either 1 or 2 days before the current day, during the current day, or 1 or 2 days after the current day (see the Analysis section for Experiment 1).

of the array, was reliably poorer when compared with accuracy at most positions $[3($ mean $=7.19 \mathrm{~cm}), 5($ mean $=$ $8.9 \mathrm{~cm}), 8($ mean $=8.79 \mathrm{~cm}), 11($ mean $=9.92 \mathrm{~cm}), 12$ $($ mean $=10.01 \mathrm{~cm})]$ inside the array $($ all $p \mathrm{~s}<.05)$. To clarify the effects of test location, a follow-up ANOVA was conducted. We classified goal positions as being either far from or near landmarks in the array. Test locations were categorized as far if the minimum distance between any of the three landmarks and the specified goal location was greater than $17 \mathrm{~cm}$ (Positions 1, 4, 5, 6, 8, 9, 11, 12 , and 14). Test locations that did not meet this criterion were categorized as near positions (Positions 2, 3, 7, 10, 13, and 15). The follow-up analysis compared accuracies for those positions within or outside the perimeter of the landmark array (as above) that also were classified as being far from or near the three landmarks. Hence, for this analysis the inside/far positions were $5,6,8,9,11$, and 12 , and the outside/far positions were 1,4 , and 13 . A within-subjects ANOVA, with bird and position as factors and distance as a dependent factor, was performed. Since accuracy did not reliably change across blocks of testing (previous analysis), we collapsed the data for this analysis across blocks. The results revealed that the nutcrackers were reliably less accurate at positions outside and far from $($ mean $=14.59 \mathrm{~cm})$ the landmarks than for positions that tended to be clustered inside the center $($ mean $=9.76 \mathrm{~cm})$ of the landmark array $[F(1,4)=9.24$, $p<.05]$.

\section{Discussion}

When presented with an apparently difficult task, the nutcrackers searched accurately for the goal. Specifically, a correct solution required the birds to ignore global cues and use the memory of the relative spatial relationship(s) between the landmark array and the goal provided during the three samples (local cues). Although the performance by these nutcrackers appeared impressive, the failure to detect a significant effect of block suggests that the birds may have had some systematic pattern of search that was independent of the position of the sample. If this was the case, our outlier analysis (see the Method section) would naturally select for a distribution of digs that was closer to the goal on that trial than the location of a goal during a previous trial. This possibility can be rejected for a number of reasons. Less than $5 \%$ of the data was excluded in the outlier analysis. The relatively small number of outliers, combined with the fact that the global position of the goal often changed dramatically from trial to trial, 

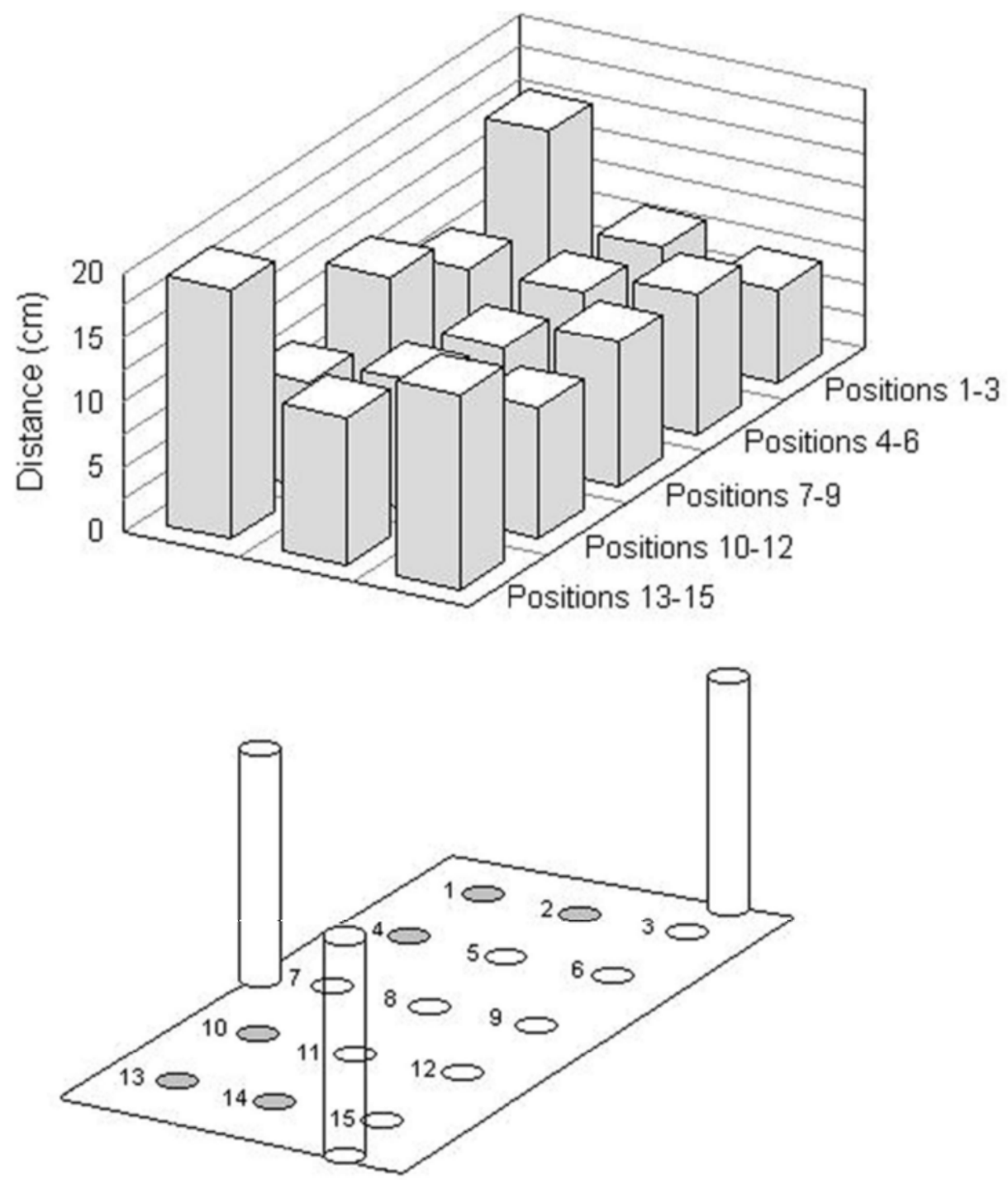

Figure 4. Top: Accuracy at each of the 15 goal locations across birds and blocks in Experiment 1. Each row of positions is indicated by a different shade for clarity. Bottom: Diagram showing the positions of the goal locations and the landmarks for reference with the top panel of this figure. The filled circles indicate positions located outside the perimeter of the landmark array.

indicates that the nutcrackers were searching for the location of the goal on that trial and not generally in the vicinity of the array. In addition, the nutcrackers were finding the goal approximately $75 \%$ of the time across the first 5 days.

A variety of factors may have contributed to the initial and sustained high level of accuracy. All the nutcrackers had previous experience in other projects in which local cues were used to locate a goal. This experience may have facilitated the immediate use of local cues during this experiment and/or contributed to increased familiarization with the experimental procedures. Correspondingly, accuracy during the first block in the present experiment was impressive $(10 \mathrm{~cm}$, on average) and was consistent with final performance in a number of other projects with Clark's nutcrackers (Gould-Beierle \& Kamil, 1996, 1998; Kamil \& Jones, 1997). In addition, the nutcrackers had the opportunity to learn about the relative location of the goal during the first three samples (when accuracy was not measured). Accuracy during the test may have been relatively high during the first block, owing to this recent and repeated experience.

Although local cues were used during navigation, the specific goal-landmark geometric relationships that were encoded remain unclear. In part, this is because the geometrical relationships between the landmarks and the goal can be defined in a number of ways (Gallistel, 1990). Spetch et al. (1997) trained pigeons to locate a goal that was buried at the geometric center of an array of four landmarks that had been placed to form a square. Infor- 
mation that could be encoded and used during search included (1) absolute information (i.e., a fixed compass direction and distance between the goal and one or more of the landmarks), or (2) relative information (i.e., the apparent angular distance between two or more of the landmarks). During some expansion tests in which the distance between the landmarks was doubled, most pigeons tended to ignore relative bearings among the landmarks but, rather, dug at locations defined by the absolute bearing during probe tests.

Absolute and relative bearings were also available to nutcrackers during Experiment 1. In absolute terms, the goal was located a certain compass direction from one or more landmarks with respect to a fixed directional bearing (e.g., due north). For example, when the goal was located at Position 4 and the landmark array was oriented as shown in Figure 1 (left and right panels, Trial 1), there were three absolute bearings from each landmark to the goal: (1) west of the white landmark, (2) southeast of the green landmark, and (3) southwest of the yellow landmark. When the orientation of the array changed during each trial of the session (Figure 1, right panel, Trials 2-4), the application of any one of these absolute bearings would have led to inaccuracy in navigation. For example, if the nutcracker used the aforementioned west bearing during Trial 2, it would still search in an area just west of the white landmark (Figure 1, right panel, Trial 2 [A]), even though the goal location had been rotated approximately $30^{\circ}$ clockwise with the array between the first and the second trials. In contrast, relative bearings would remain valid following reorientation of the landmark array from trial to trial. At Position 4, there was an angular distance of approximately $125^{\circ}$ between the white and the green landmarks. As the orientation of the array changed, this relationship would remain unchanged during each trial, and the nutcrackers could have used the same relative bearings between the white and the green landmarks and searched in the correct direction of the goal (Figure 1, right panel, Trial $2[\mathrm{R}])$. This would be an example of using configural information about the relative arrangement of landmarks in space. Navigation could have also been performed by using a compass (e.g., Wiltschko \& Balda, 1989); the nutcrackers could have calculated a bearing toward the goal by subtracting the degree of rotation of the array with respect to a compass bearing from the angular distance between two or more landmarks. Although previous studies have suggested the use of relative bearings by nutcrackers (Kamil \& Jones, 1997) and other animals (Spetch et al., 1997), the data from Experiment 1, along with other unpublished data (Kamil \& Jones, 2000), confirm the use of relative information by nutcrackers during a complex searching task.

Unlike other open-room studies of navigation (see Cheng \& Spetch, 1998; Shettleworth, 1998), the present experiment utilized a large number of goal locations. This feature of our design allowed for the comparison of accuracy at multiple sites that had unique spatial relationships with the landmarks of the array. As was expected, search accuracy varied reliably with goal location. One concern may be that differences in accuracy observed between positions inside and outside the array could be due to apparent differences in the number of positions in each of these sets of positions. That is, the subjects may have had more experience with positions inside the array and subsequently located them better. Although we operationally defined all positions within the perimeter of the array as being inside, this distinction is somewhat arbitrary. Positions 5 and 7 fall on the line between the white and the green landmarks and may not be classified by the animals as being inside or outside. If we do not consider positions on the line (either inside or outside) connecting the white and green and the white and yellow landmarks, the subjects experienced as many positions deep inside the array $(6,8,9,11$, and 12) as they did far outside the array $(1,2,4,10,13$, and 14). The statistical analysis of the position data takes this point into consideration and primarily examines performance at positions in the extremities of the inside and outside sets. Hence, it seems unlikely that the birds' improved performance for positions inside the array was due to spatial generalization.

In both open-room (Bennet, 1993) and operant (Spetch, 1995) search paradigms, search accuracy has been shown to be improved when a goal is closer to a landmark(s) than when it is far. Although accuracy would appear to decrease proportionally as the distance between a goal and a landmark is increased, other factors may also influence performance. Indeed, in the present experiment, accuracies at positions classified as being far and outside the array were poorer than those at positions classified as being far and inside the array. A landmark's features (Bennet, 1993), the goal-array geometry, and the configuration of the array may all influence search accuracy. Perhaps, while inside and near the center of the array, the nutcrackers were able to use information from two or more landmarks to improve search accuracy (Kamil \& Cheng, 2001). Specifically, one way in which the birds may have located the goal is by summing navigational vectors (Cheng, 1988,1989,1990) from two or more landmarks. According to this view, a navigational vector from each of three landmarks specifies the unique location of the goal. Although direction and distance are likely remembered, directional information plays a primary role for nutcrackers. In several experiments (Kamil \& Jones, 1997, 2000, nutcrackers were more accurate in determining the direction than in determining the distance of a goal from a landmark. With this in mind, the nutcrackers may have combined each of these three directional vectors to return to the goal location. Although information from only two of the three landmarks is needed to unambiguously specify the location of the goal, information from an increasing number of landmarks may improve search accuracy (Kamil \& Cheng, 2001). The birds may have been more likely to encode more than two navigational vectors for some goal positions, but fewer than two vectors for other positions. Accuracy for positions in the center of the array tended to be quite good. 
The distance between each of the landmarks and the goal was similar at these positions and may have resulted in the navigational vectors from all three landmarks being weighted equally and used during search for the goal. In contrast, information from only one landmark may have been used for positions far outside the perimeter of the array, since the other two landmarks in the array were farther away and may have been weighted less (Cheng, 1989). If this were the case, future tests designed to systematically manipulate the number of landmarks near a goal might be of interest.

Search may be very accurate when the position of a goal is at the base of a landmark. In this case, a single landmark may be used as a beacon (Shettleworth, 1998). In the present experiment, Positions 3, 7, 10, and 15 were less than $7 \mathrm{~cm}$ from the base of a landmark. Accuracy at two of these four positions $[3$ (mean $=7.19)$ and 10 (mean $=8.08)$ ] was much lower than accuracy at positions considerably farther away. This finding is consistent with the decline in accuracy at the shortest distances between a landmark and a goal occasionally reported elsewhere (e.g., Kamil \& Jones, 1997). From our observations, it appeared that when testing was conducted at Positions 7 and 15 , the nutcrackers identified the correct landmark but often dug in a circumference around the landmark. Perhaps, when the landmark was too close to the goal, the nutcrackers had difficulty obtaining an accurate bearing from the landmark (Benhamou \& Poucet, 1998). Specifically, use of a single landmark would still require a directional bearing to accurately locate the goal. For example, if the nutcrackers were obtaining a directional fix from the east portion of the room, where a number of salient global landmarks were located, the landmark adjacent to Positions 7 and 15 may have blocked the nutcracker's field of view more frequently, perhaps making it more difficult to obtain a directional fix from either a landmark in the array or some global feature of the room.

The results of Experiment 1 demonstrated that nutcrackers could learn to solve an open-room task that required them to ignore information about the global environment and use relative local information from the three landmarks to locate a goal among a large number of potential goal locations. The task was made even more challenging because the correct location relative to the landmark array changed across sessions. Some of the features of the present study (e.g., the animal was required to match the sample location with the test location on the choice test) are similar to those used in DMTS. Hence, manipulations common to operant DMTS might prove useful in the present investigations. In Experiment 2, we examined the effect on response accuracy of varying the number of sample presentations prior to the test, a manipulation common in DMTS.

\section{EXPERIMENT 2}

Previous studies using DMTS have found that increasing the duration of the sample presentation (Nelson $\&$ Wasserman, 1978) or the response requirement to the sample (Foster, Temple, Mackenzie, DeMello, \& Poling, 1995; Sacks, Kamil, \& Mack, 1972) improves performance during a subsequent choice test. Increasing the duration of the samples may facilitate better storage of the stimulus events, whereas increasing the response requirement may increase the cost of incorrect responding. In Experiment 1, we provided three samples prior to the test. This procedure initially appeared necessary to dissociate the global and the locally defined location of the goal within sessions. Since the orientation of the array changed with each trial of the session, only relative cues would accurately indicate the location of the goal. Thus, multiple rotations within sessions invalidated absolute bearings and forced the use of relative relationships. The use of multiple samples may have effects similar to the effect of increasing the duration of sample exposure-that is, additional exposure to the spatial information necessary to locate the goal, combined with further exposure to the rotating array, may improve accuracy during the test. Alternatively, the presentation of a second or third sample may interfere with search, since the birds are presented with additional global cues that they must ignore. In Experiment 2, we explored these possibilities by varying the number of samples (one to three) the nutcrackers received prior to the matching test.

\section{Method}

\section{Subjects and Apparatus}

The same birds as those trained and tested in Experiment 1 were used in Experiment 2. Tests were conducted in the same room, and the landmark array was the same as that used in the previous experiment.

\section{Procedure}

The procedures used in Experiment 2 were identical to those used in Experiment 1, except that instead of three samples, one, two, or three samples were given prior to a test. Testing occurred in three 10-session blocks, for a total of 30 sessions. The number of samples presented was balanced across blocks, so that every bird experienced each of the three sample conditions 10 times. The nutcrackers were not allowed to experience more than 2 sessions in a row with the same sample number. Likewise, no more than 2 nutcrackers were permitted to be tested with the same number of samples on a given day.

As in Experiment 1, all 15 target locations were used. The number of samples presented at each test location was balanced across birds and blocks. Counterbalancing of position was incomplete, however, since no individual was tested with every test location $\times$ sample number combination. As in Experiment 1, the position of the array was allowed to move randomly across the samples and the test. Each bird experienced one session per day.

\section{Analysis}

A within-subjects ANOVA, with sample number, block, and bird as factors and accuracy as a dependent measure, was used to explore whether varying the number of samples prior to the test influenced search accuracy. An additional ANOVA was performed to explore the effects on performance of the position of the goal within the test area. Bonferroni pairwise comparisons were used where appropriate.

\section{Results and Discussion}

Figure 5 shows that search accuracy, as defined in Experiment 1 , was not affected by the number of samples 


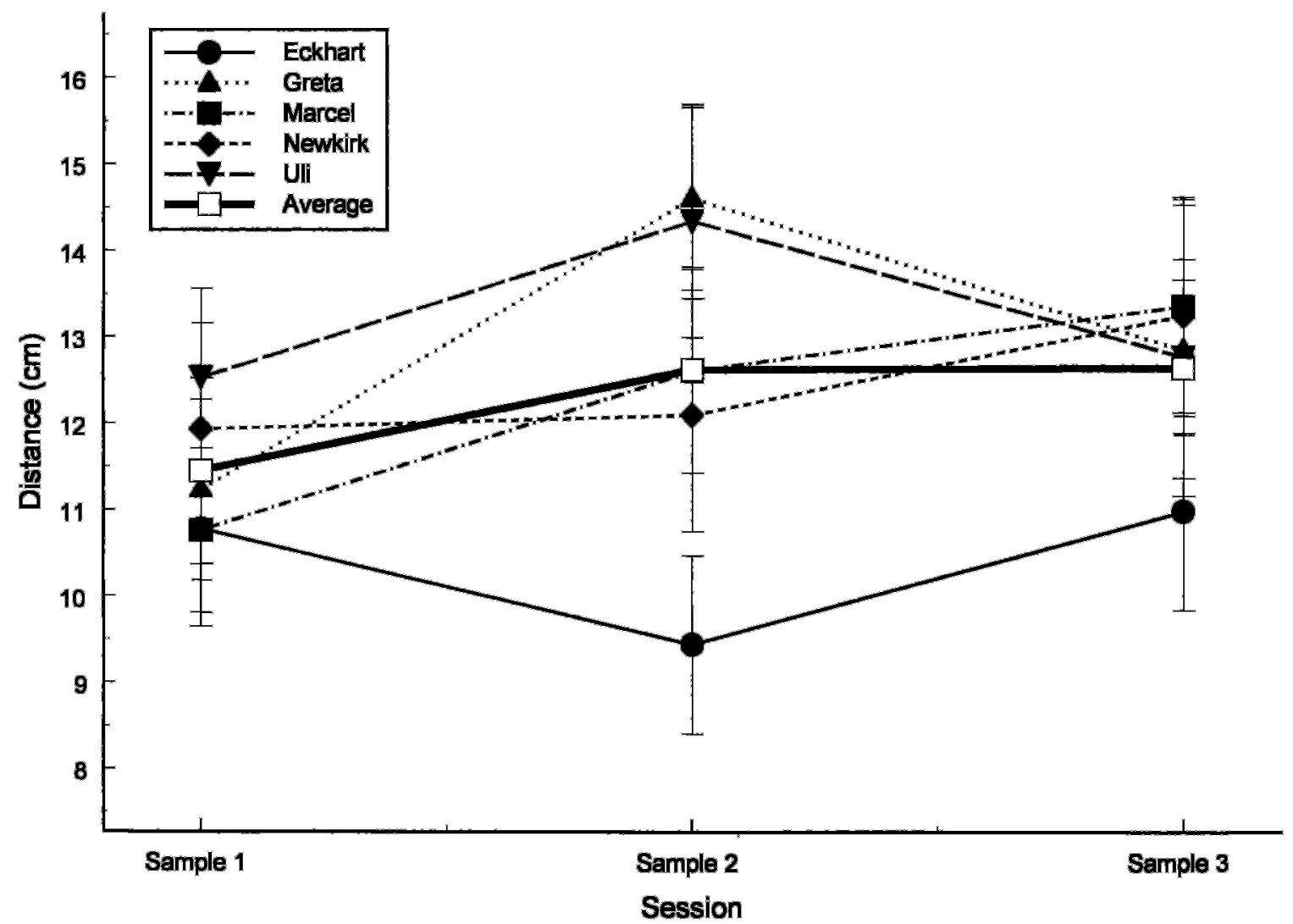

Figure 5. The effect of showing one, two, or three spatial samples prior to the test on the average distance of digs from the goal for each nutcracker.

presented $[F(2,8)=1.46, p>.05]$. There was also no significant change in accuracy across blocks $[F(2,8)<1]$. In contrast to the results of Experiment 1, there were no significant effects of goal location $[F(14,105)=1.14, p>$ .05 ; see Figure 6]. It appeared that accuracy at some sites on the perimeter of the array increased from the first experiment (e.g., for Position 1, there was a mean of $14.52 \mathrm{~cm}$ vs. a mean of $15.54 \mathrm{~cm}$ in Experiment 1), whereas accuracy at some positions within the array declined somewhat when compared with performance during Experiment 1 (e.g., for Position 12, there was a mean of $12.58 \mathrm{~cm}$ vs. a mean of $10.01 \mathrm{~cm}$ in Experiment 1). As in Experiment 1 , accuracy at Positions $1($ mean $=14.52 \mathrm{~cm})$ and 13 $($ mean $=15.89 \mathrm{~cm})$ tended to be numerically among the lowest, whereas accuracy at positions in the center of the array [e.g., $8($ mean $=10.4 \mathrm{~cm})$ ] still tended to be among the highest. Although there was a significant interaction between test location and the number of samples presented prior to testing $[F(14,28)=1.61, p<.05]$, Bonferroni post hoc comparisons, examining performance separately at each of the 15 locations for each of the three samples, failed to reveal a reliable difference between any of the position $\times$ sample combinations (all $p \mathrm{~s}>.05$ ). A series of follow-up ANOVAs that independently assessed the effect of each of the sample conditions at each of the 15 test locations also failed to reveal an effect of presenting one, two, or three samples at any of the 15 test locations [all $\left.F_{\mathrm{s}}(14,28)<1\right]$. In view of the small amount of variance associated with this effect and the failure of follow-up comparisons to reveal similar differences, it is probably best ignored.

Considering the dynamic change in spatial cues from trial to trial, it is somewhat surprising that the nutcrackers performed so well with only one sample. One possibility is that the nutcrackers learned the procedures during Experiment 1 and needed only one sample to perform well in Experiment 2. In addition, during each sample, we presented the nutcrackers with valid information (the goal location relative to the landmarks) and invalid information (goal location relative to everything else in the room); each repeat of a sample made both relationships stronger, leading to no overall change in accuracy. Perhaps only brief exposure to the relationships between the landmark array and the goal is necessary for encoding by Clark's nutcrackers. The nutcracker's natural environment may provide some clues as to why this may be so. Nutcrackers make a large number of caches in a relatively short period of time. The amount of time they can spend observing the geometric relationships between a cache and the landmarks surrounding it appears to be 

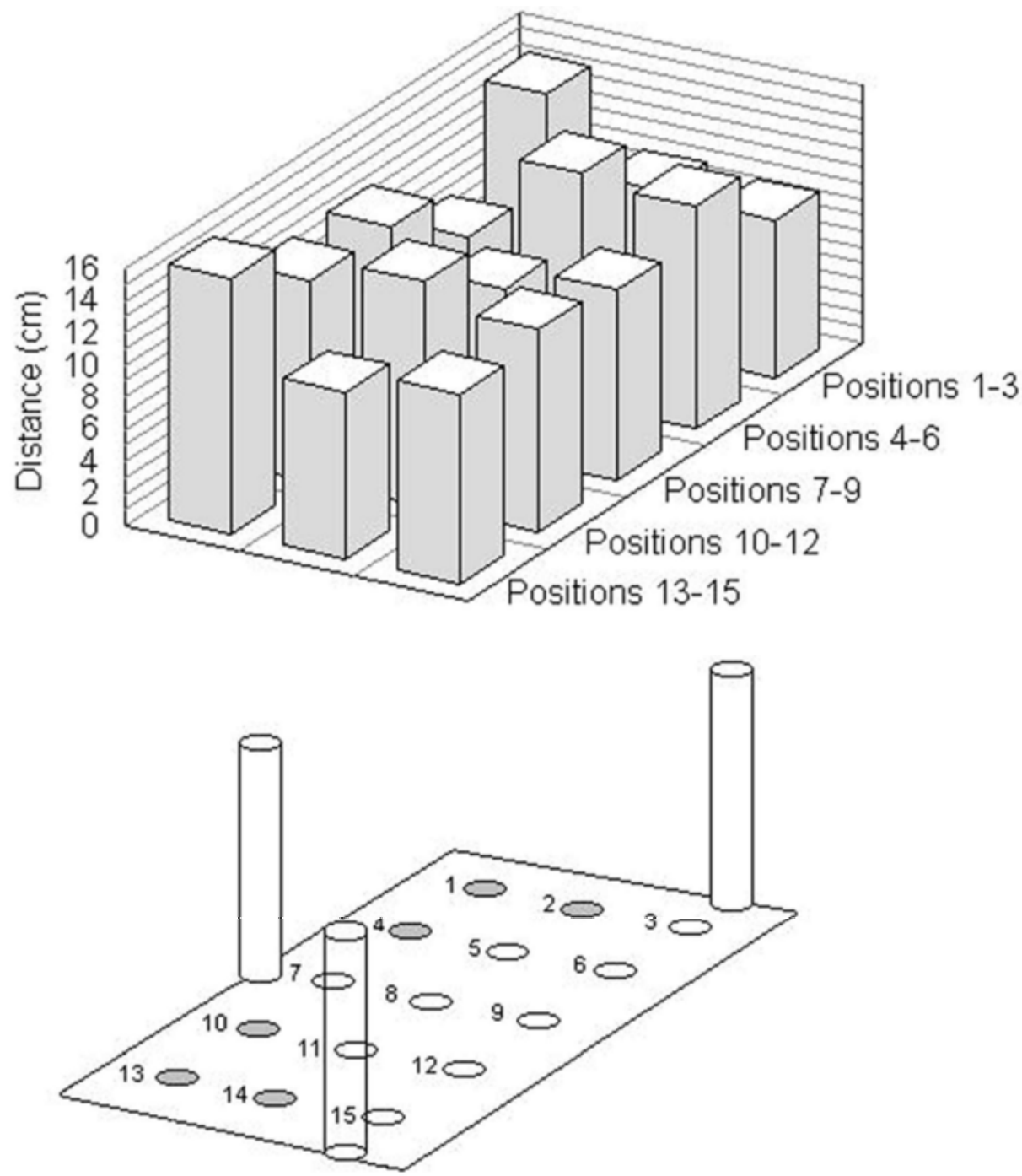

Figure 6. Top: Accuracy at each of the 15 goal locations across birds and blocks in Experiment 1. Each row of positions is indicated by a different shade for clarity. Bottom: Diagram showing the positions of the goal locations and the landmarks for reference with the top panel of this figure. The filled circles indicate positions located outside the perimeter of the landmark array.

limited. A nutcracker that spends an excessive amount of time at a cache site may provide other animals with information about the location of its cache and make it more susceptible to pilfering. Alternatively, experience our nutcrackers had with other spatial tasks in other studies (Gould-Beierle \& Kamil, 1996) may have assisted them in their performance during Experiment 2. Finally, it is possible that the nutcrackers were less motivated to search at locations at which they had previously recovered food, thus negating any increase in spatial accuracy obtained by seeing multiple samples at the same spatial location. Our work with nutcrackers in other projects (e.g., Gibson $\&$ Kamil, in press), however, indicates that nutcrackers are quite motivated to search for hidden food and are consistently accurate even when they are required to return to the same spatial location repeatedly.
Accuracy for positions within the test area tended to be more homogenous than that found in Experiment 1. Specifically, accuracy at some of the sites on the perimeter of the array (e.g., Position 14) improved, and accuracy at some positions within the array (e.g., Positions 5 and 11) tended to decrease somewhat.

\section{EXPERIMENT 3}

During the first two experiments, some nutcrackers dug far away from the correct location at the beginning of some tests but dug close to the goal just before the trial limits were imposed. It may be that the nutcrackers knew the correct location at the beginning of a trial but elected to dig at other locations in the room to explore the environment (Bednekoff \& Balda, 1997; Kamil \& Balda, 


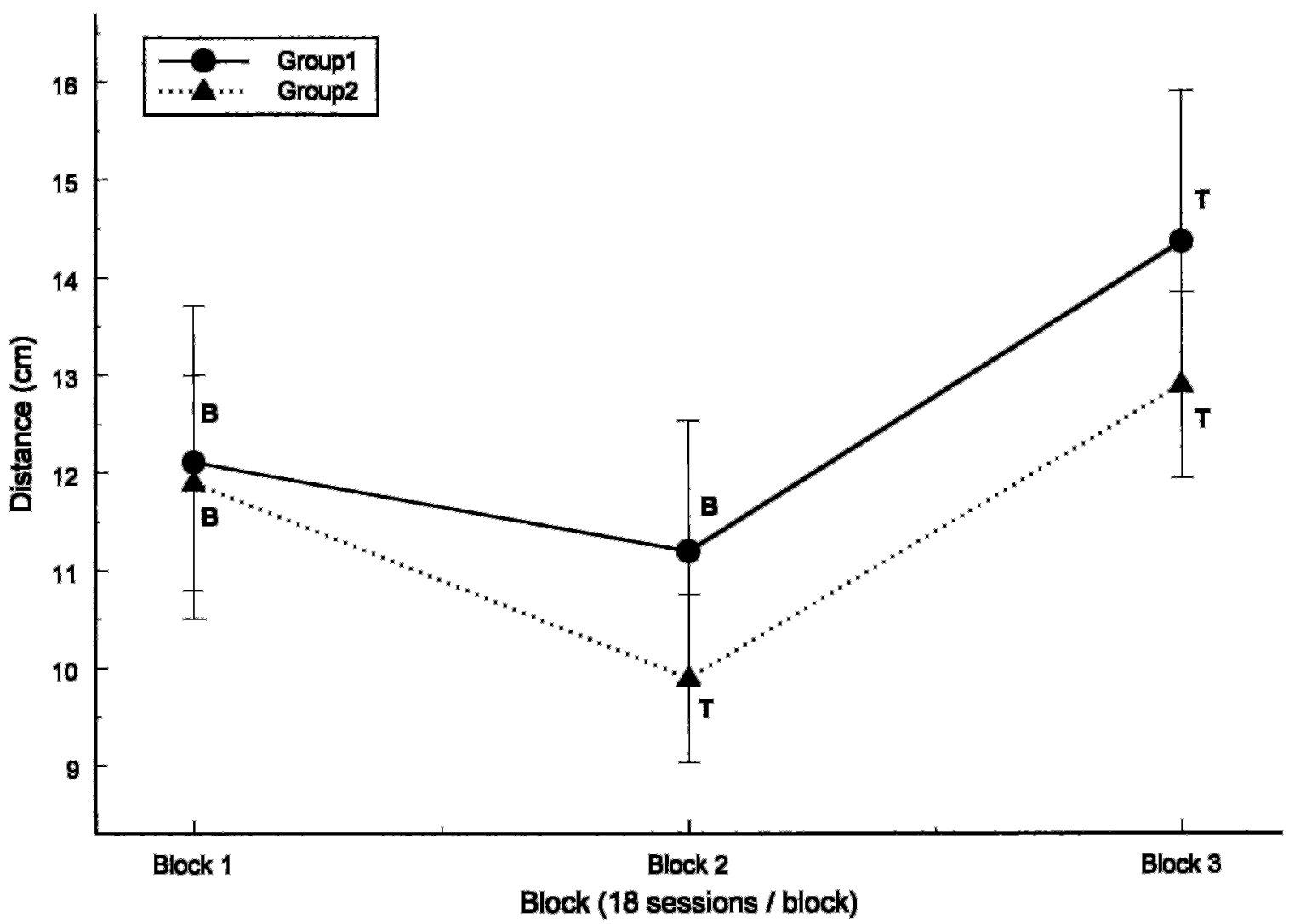

Figure 7. The effect of baseline (100 permitted digs) and cost-increasing (20 digs) procedures on accuracies for the nutcrackers in Group 1 and Group 2. B, baseline; T, increased cost test.

1990). That is to say, the cost of inaccurate digging early in the test may have been small, but it may have increased near the conclusion of the test if food had yet to be found. This potential strategy would have had the effect of making the first $20 \mathrm{digs}$ on some trials relatively inaccurate. In Experiment 3, we examined the effect of increasing the relative cost of responding during search, using a multiple-baseline design. We attempted to increase search accuracy by limiting the number of digs that could be made during the test and by introducing a time-out penalty following the initial 20 digs made during the test.

\section{Method}

\section{Subjects and Apparatus}

The birds, room, and landmark array were identical to those used in the previous experiments.

\section{Experimental Design}

A multiple-base line design (Ray \& Ravizza, 1988) was employed. The birds underwent baseline or increased cost procedures, as described below, during sequential blocks of testing. Testing was divided into three 18 -trial blocks. Prior to testing, the nutcrackers were randomly separated into two groups. During Block 1, both groups underwent baseline procedures. During Block 2, the 2 birds making up Group 1 (Newkirk and Greta) continued to undergo baseline procedures, whereas the birds in Group 2 (Marcel, Uli, and Eckhart) were tested in the increased cost condition. In Block 3, both groups experienced increased cost procedures. The staggered feature of the multiple-baseline design allowed us to compare the effects of the manipulation on one group while the other group simultaneously served as a control.

\section{Procedures}

The procedures used in Experiment 3 were similar to those used in Experiments 1 and 2. Because the results of Experiment 2 revealed that performance did not change with the presentation of more than one sample, only one sample was presented prior to a test in Experiment 3. During testing in the baseline condition, the nutcrackers were presented with one spatial sample and then allowed to reenter the room on the test and make up to 100 digs. The nutcracker's average accuracy (first 20 digs) during this block served as a baseline measure of performance. During testing in the increased cost condition, the nutcrackers were presented with a single sample and then allowed to reenter the room and make up to 20 digs during the matching test. If the goal was not found within 20 digs, the houselights were turned off, and the bird was allowed to return to the transfer cage. Following a 2-min time-out period, the lights illuminating the transfer cage were turned off, the slide door was opened, and the bird was allowed to reenter the test room and make an additional 20 digs. If the bird located the buried goal on the first entry of the test or after 20 more digs on the second entry, the room lights were turned off, and the bird was returned to its home cage in the colony. The nutcrackers that did not find the seeds dur- 

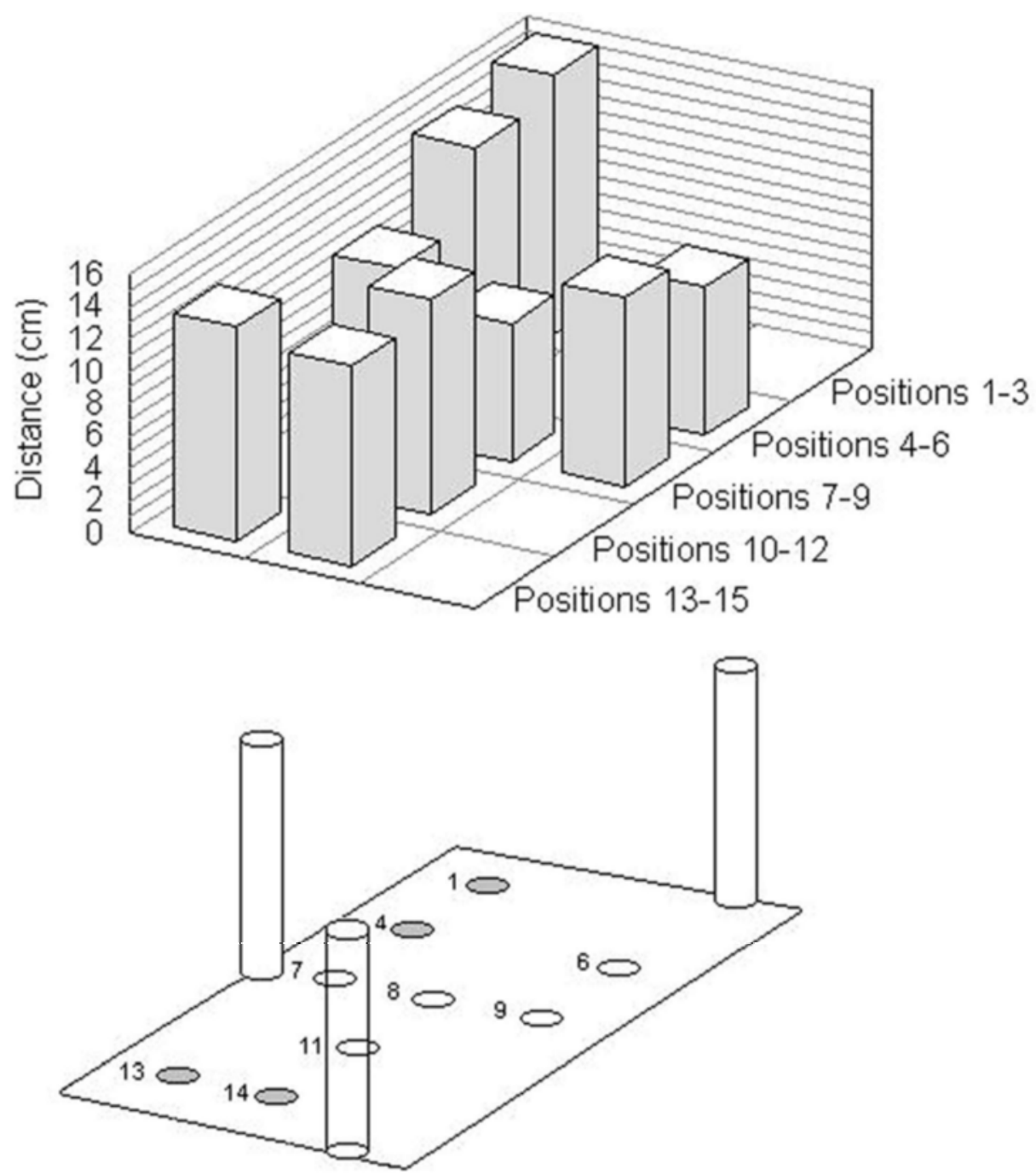

Figure 8. Top: Accuracy at each of the nine goal locations across birds and blocks in Experiment 1. Each row of positions is indicated by a different shade for clarity. Bottom: Diagram showing the positions of the goal locations and the landmarks for reference with the top panel of this figure.The filled circles indicate positions located outside the perimeter of the landmark array.

ing the reentry period were returned to the home colony. The birds were tested twice per day. The order in which the birds were tested was determined randomly prior to testing.

In contrast to Experiments 1 and 2, only 9 of the 15 target locations $(1,4,6,7,8,9,11,13$, and 14) were used in Experiment 3. These locations were well dispersed within the test area, and performance at each location was consistent and reflected the variation in performance at sites seen in the previous two experiments. The order in which test locations were used was selected randomly, and no more than 2 nutcrackers were tested at the same position on a given day. One test location was used per nutcracker per day.

\section{Analysis}

Consistent with the multiple-baseline design, individual comparisons of accuracy (averaged across each block) were made among the birds at each block of testing. As with the previous two experiments, an ANOVA was also used to test for significant differences in accuracy at each of the nine test locations. Bonferroni pairwise comparisons were used for follow-up analyses for the comparison of performance at specific sites.

\section{Results and Discussion}

During the first baseline block of trials, mean accuracies were similar for all 5 nutcrackers (Figure 7). Accuracies for the 2 nutcrackers that continued with baseline procedures through the second block remained relatively unchanged from Block 1 . In comparison, all 3 of the nutcrackers that underwent cost-increasing procedures in Block 2 showed modest improvements in accuracy, as compared with their performance during baseline in Block 1. During Block 3, in which all the nutcrackers underwent cost-increasing procedures, accuracies for all 3 nutcrackers in Group 2 decreased and returned to levels similar to those encountered in Block 1. Accuracy for both 
of the nutcrackers in Group 1 also declined from Block 2, when baseline was last measured. For one nutcracker (Greta), this decline in accuracy far surpassed the level of performance recorded during baseline. Because accuracy across the conditions was similar and because the sample size was relatively small, the analysis of the effects of the cost-increasing procedures was not pursued beyond this descriptive analysis. Finally, mean accuracy during the first set of 20 digs (mean $=12.87$ ) was nearly identical to mean accuracy when a second set of 20 digs (mean $=12.70)$ was required.

Since accuracy did not appear to be influenced by the cost treatment, accuracies at each of the nine test locations used in Experiment 3 were averaged across blocks and subjected to a repeated measures ANOVA, with position as an independent factor and bird as a repeated factor. As in Experiment 1, accuracy varied reliably with test position $[F(9,36)=2.97, p<.05$; see Figure 8]. Bonferroni follow-up comparisons revealed that the nutcrackers were significantly more accurate (all $p \mathrm{~s}<.05)$ at Positions $6($ mean $=9.17 \mathrm{~cm})$ and $8($ mean $=8.55 \mathrm{~cm})$ than when the goal was at Position $1($ mean $=15.98 \mathrm{~cm})$. No other significant differences among performance at each of the test positions were found $(p \mathrm{~s}>.05)$.

As in Experiment 1, a follow-up ANOVA was undertaken to compare performance at locations classified as being either outside and far from (Positions 1 and 13) or inside and far from (Positions 6, 7, 8, 9, and 11) the landmarks in the array. As in Experiment 1, performance was significantly better at position s that were far from but inside the landmark array $($ mean $=10.34 \mathrm{~cm})$ than at positions that were far from but outside $($ mean $=15.34 \mathrm{~cm})$ the array $[F(1,4)=7.57, p<.05]$.

Although the results from Experiment 3 give no consistent indication of an effect of response cost on search accuracy in this spatial search task, such effects have been found in other experiments (however, see Brodbeck, Burack, \& Shettleworth, 1992). For example, a number of delayed response tasks have reported that increasing the response effort required to produce reward improves choice accuracy during a test (e.g., Brown \& Huggins, 1993; Sacks et al., 1972). Likewise, similar results have been found in tests of spatial memory using cache recovery procedures with nutcrackers. Kamil and Balda (1990) found that cache recovery accuracy improved when caches were made and recovered in a gravel substrate, which presumably increased the effort required to make and retrieve caches, than when caches were made and recovered in a fine-grained sand. Perhaps the additional costs we imposed for excessive digging were not sufficient to improve performance. Bednekoff and Balda (1997) reported that, in general, nutcrackers were less likely to make errors during a cache recovery session when costs were imposed by covering sand-filled cache recovery sites with either petri dishes or glass bowls.

As in Experiment 1, performance varied with the location of the goal. In both experiments, accuracies at Positions 1 and 13 were much worse than those at other lo- cations. The disparity in performance cannot be attributed solely to increased distance from the landmarks, however. Performance at positions in the center of the array was reliably better than that at positions outside the array (1 and 13) that were just as far from the landmarks (both Experiments 1 and 3).

\section{GENERAL DISCUSSION}

The results of these three experiments have revealed some aspects of the nutcrackers' ability to encode, remember, and navigate toward important locations in space. One such finding was that the location of a goal relative to the landmark array had an impact on search accuracy. Previous studies have indicated that navigation or search may be less accurate when a landmark(s) is farther from a goal than when it is close (e.g., Bennet, 1993; Spetch, 1995). For nutcrackers, factors other than the relative distance between a landmark and the goal are important in the accuracy of search. In Experiments 1 and 3 , accuracy declined when nutcrackers were tested at Positions 1 and 13 (far and outside), as compared with performance at all other positions. This pattern also emerged in Experiment 2 but reached statistical significance only for the first test location. However, in Experiments 1 and 3 , accuracy was reliably better when testing was conducted at positions that were classified as being far and inside the landmark array (generally, the center of the array) than at positions classified as being far and outside the landmark array. The pattern of performance at test locations suggests that nutcrackers may be using different combinations of information from landmarks during search. As was previously mentioned, some nutcrackers may use a single relative bearing when the goal is very close to some landmarks in the array. As the distance between the goal and an individual landmark increases, however, any inaccuracy in bearing magnifies inaccuracy during search (Kamil \& Cheng, 2001). Perhaps, at positions inside the array, nutcrackers use the information from two or more landmarks to obtain a cross-fix of the goal location, reducing inaccuracy in bearing and resulting in more accurate search (Gallistel, 1990). In contrast, when nutcrackers are tested at positions far outside the array, information from two or more landmarks may be weighted less (Cheng, 1989), and they again resort to using cues from a single landmark to locate the goal. These findings indicate that further studies with these techniques are of potential value.

The present procedures were based, in part, on ideas from DMTS and radial maze designs. Although our procedures revealed interesting information about nutcracker spatial behavior, two important phenomena characteristic of DMTS were not observed: the effects of increasing sample exposure or number of presentations (Experiment 2) and the effects of increasing the cost of responding (Experiment 3). This discrepancy may stem from one or more of the procedural differences between our method and those of other DMTS studies. One such dif- 
ference is the nature of the response alternatives during the test. Whereas DMTS uses discrete alternatives, the animals in the present experiments did not have a fixed number of alternatives to choose from when digging in the substrate. Although this would have been possiblefor example, by making each of the 15 potential goal locations visible - it would have reduced the extent to which spatial navigation was being tested. In addition, with the procedures we employed, search accuracy was a function of both the accuracy of memory and the ability to translate that memory into accurate search.

The present procedures seem akin to some features of radial maze designs. In these studies, animals are presented with and allowed to choose from a large number of spatially unique locations during a test. However, there are some important differences between radial maze designs and the present procedures. Unlike standard radial maze designs, the nutcrackers were able to move freely in the room during search for the goal. In addition, the landmark information defining the location of the goal moved in the room from trial to trial, which appears to be uncommon with the radial maze. Finally, whereas other experiments (Brown \& Huggins, 1993) have found an effect of increased response effort on choice accuracy in the radial maze, the present procedures failed to reveal such an effect (Experiment 3).

Using an open-room delayed matching test, the present set of experiments explored how search accuracy varied at goal positions that had unique spatial relationships with a landmark array. The observation that search accuracy varied with respect to goal-landmark geometry suggests that future studies designed to further explore the role of goal location with respect to an array of landmarks would be of interest. Specifically, such studies might identify the type of geometric information that is used to direct search when different sets of landmarks are presented.

\section{REFERENCES}

BALDA, R. P., \& KAMIL, A. C. (1992). Long-term spatial memory in Clark's nutcracker, Nucifraga columbiana. Animal Behaviour, 44, 761-769.

BALDA, R. P., \& KAmiL, A. C. (1998). The ecology and evolution of spatial memory in corvids of the southwestern USA: The perplexing pinyon jay. In R. P. Balda, I. M. Pepperberg, \& A. C. Kamil (Ed.), Animal cognition in nature: The convergence of psychology and biology in laboratory and field (pp. 29-64). San Diego: Academic Press.

BASIL, J. A. (1993). Neuroanatomical and behavioral correlates of spatial memory in Clark's nutcrackers. Unpublished doctoral dissertation, University of Massachusetts, Amherst.

Beatty, W. W., \& Shavalia, D. A. (1980). Spatial memory in rats: Time course of working memory and effects of anesthetics. Behavioral \& Neural Biology, 28, 454-462.

Bednekoff, P. A., \& BALDA, R. P. (1997). Clark's nutcracker spatial memory: Many errors might not be due to forgetting. Animal Behaviour, 54, 691-698.

Benhamou, S., \& Poucet, B. (1998). Landmark use by navigating rats (Rattus norvegicus): Contrasting geometric and featural information. Journal of Comparative Psychology, 112, 312-322.

BenNet, A. T. D. (1993). Spatial memory in a food-storing corvid: I. Near tall landmarks are primarily used. Journal of Comparative Physiology A, 173, 193-207.

Brodbeck, D. R. (1994). Memory for spatial and local cues: A com- parison of a storing and a nonstoring species. Animal Learning \& Behavior, 22, 119-133.

Brodbeck, D. R., Burack, O. R. \& Shettleworth, S. J. (1992). Onetrial associative memory in black-capped chickadees. Journal of Experimental Psychology: Animal Behavior Processes, 25, 334-351.

Brown, M. F., \& Huggins, C. K. (1993). Maze-arm length affects a choice criterion in the radial-arm maze. Animal Learning \& Behavior, 21, 68-72.

Cartwright, B. A., \& Collett, T. S. (1983). Landmark learning in bees: Experiments and models. Journal of Comparative Physiology A, 151, 521-543.

Catania, C. A. (1992). Learning (3rd ed.). Englewood Cliffs, NJ: Prentice-Hall.

Cheng, K. (1988). Some psychophysics of the pigeon's use of landmarks. Journal of Comparative Psychology, 162, 815-826.

Cheng, K. (1989). The vector sum model of pigeon landmark use. Journal of Experimental Psychology: Animal Behavior Processess, 15, 366-375.

Cheng, K. (1990). More psychophysics of the pigeons's use of landmarks. Journal of Comparative Physiology A, 166, 857-863.

Cheng, K., \& Spetch, M. L. (1998). Mechanisms of landmark use in mammals and birds. In S. Healy (Ed.), Spatial representation in animals (pp. 1-17). Oxford: Oxford University Press.

Chittka, L., Geiger, K., \& Kunze, J. (1995). The influences of landmarks on distance estimation of honey bees. Animal Behaviour, 50, 23-31.

Collett, T. S., Cartwright, B. A., \& Smith, B. A. (1986). Landmark learning and visuo-spatial memories in gerbils. Journal of Comparative Physiology A, 158, 835-851.

Foster, T. M., Temple, W., Mackenzie, C., DeMello, L. R., \& PolING, A. (1995). Delayed matching-to-sample performance of hens: Effects of sample duration and response requirements during the sample. Journal of the Experimental Analysis of Behavior, 64, 1931.

Gallistel, C. R. (1990). The organization of learning. Cambridge, MA: MIT press.

GiBson, B. M., \& KAmIL, A. C. (in press). Tests for cognitive mapping in Clark's nutcrackers (Nucifraga columbiana). Journal of Comparative Psychology.

Giuntoli, M., \& Mewaldt, L. R. (1978). Stomach contents of Clark's nutcrackers collected in western Montana. Auk, 95, 595-598.

Gould-Beierle, K. L., \& Kamil, A. C. (1996). The use of local and global cues by Clark's nutcrackers (Nucifraga columbiana). Animal Behaviour, 52, 519-528.

Gould-Beierle, K. L., \& Kamil, A. C. (1998). Use of landmarks in three species of food-storing corvids. Ethology, 104, 361-378.

KAMIL, A. C., \& BALdA, R. P. (1985). Cache recovery and spatial memory in Clark's nutcrackers (Nucifraga columbiana). Journal of Experimental Psychology: Animal Behavior Processes, 11, 95-111.

KAMIL, A. C., \& BALDA, R. P. (1990). Spatial memory in seed-caching corvids. In G. H. Bower (Ed.), The Psychology of learning and motivation (Vol. 26, pp. 1-25). New York: Academic Press.

Kamil A. C., \& Cheng, K. (2001). Way-finding and landmarks: The multiple-bearings hypothesis. Journal of Experimental Biology, 204, 103-113.

Kamil, A. C., \& Jones, J. J. (1997). The seed-storing Corvid Clark's nutcracker learns geometric relationships among landmarks. Nature, 390, 276-279.

KAMIL, A. C., \& JonEs, J. J. (2000). Geometric rule learning by Clark's nutcrackers (Nucifraga columbiana). Journal of Experimental Psychology: Animal Behavior Processess, 26, 439-453.

McDonald, R. J., \& White, N. M. (1993). A triple dissociation of memory systems: Hippocampus, amygdala, and dorsal striatum. Behavioral Neuroscience, 107, 3-22.

Nelson, K. R., \& Wasserman, E. A. (1978). Temporal factors influencing the pigeon's successive matching-to-sample performance: Sample duration, intertrial interval, and retention interval. Journal of the Experimental Analysis of Behavior, 30, 153-162.

OLson, D. J. (1991). Species differences in spatial memory among Clark's nutcrackers, scrub jays, and pigeons. Journal of Experimental Psychology: Animal Behavior Processes, 17, 363- 376. 
Olton, D. S., \& SAmuelson, R. J. (1976). Remembrance of places passed: Spatial memory in rats. Journal of Experimental Psychology: Animal Behavior Processess, 2, 97-116.

RAY, W. J., \& RAVIZZA, R. (1988). Methods toward a science of behavior and experience (3rd ed.). Belmont, CA: Wadsworth.

RILEY, D. A. (1968). Similarity responding by monkeys in a matching to sample task. Journal of Comparative \& Physiological Psychology, 65, 191-196.

Sacks, R. A., Kamil, A. C., \& Mack, R. (1972). The effects of fixedratio sample requirements on matching to sample in the pigeon. Psychonomic Science, 26, 291-293.

Shettleworth, S. J. (1998). Cognition, evolution and behavior. Oxford: Oxford University Press.

Spetch, M. L. (1995). Overshadowing in landmark learning: Touchscreen studies with pigeons and humans. Journal of Experimental Psychology: Animal Behavior Processes, 21, 166-181.

Spetch, M. L. , Cheng, K., MacDonald, S. U., Linkenhoker, B. A., Kelly, D. M., \& Doerkson, S. R. (1997). Use of landmark config- uration in pigeons and humans: II. Generality across search tasks. Journal of Comparative Psychology, 111, 14-24.

Tinbergen (1972). Curious naturalists. Amherst: University of Massachusetts Press.

Tомваск, D. F. (1980). How nutcrackers find their seed stores. Condor, 82, 10-19.

VANDER WALL, S. B. (1982). An experimental analysis of cache recovery in Clark's nutcracker. Animal Behaviour, 30, 84-94.

VANDER WAll, S. B., \& BALDA, R. P. (1981). Ecology and evolution of food-storage behavior in conifer-seed-caching corvids. Zeitschrift für Tierpsychologie, 56, 217-242.

Wiltschko, W., \& Balda, R. P. (1989). Sun compass orientation in seed-caching scrub jays (Aphelocoma coerulescens). Journal of Comparative Physiology A, 164, 717-721.

(Manuscript received September 28, 2000; revision accepted for publication March 27, 2001.) 